\title{
Cardiac Peroxisome Proliferator-Activated Receptor- $\gamma$ Expression is Modulated by Oxidative Stress in Acutely Infrasound-Exposed Cardiomyocytes
}

\author{
Zhaohui Pei • Rongsen Meng • Zhiqiang Zhuang • \\ Yiqiao Zhao · Fangpeng Liu • Miao-Zhang Zhu • \\ Ruiman Li
}

Published online: 1 May 2013

(c) The Author(s) 2013. This article is published with open access at Springerlink.com

\begin{abstract}
The aim of the present study was to examine the effects of acute infrasound exposure on oxidative damage and investigate the underlying mechanisms in rat cardiomyocytes. Neonatal rat cardiomyocytes were cultured and exposed to infrasound for several days. In the study, the expression of CAT, GPx, SOD1, and SOD2 and their activities in rat cardiomyocytes in infrasound exposure groups were significantly decreased compared to those in the various time controls, along with significantly higher levels of $\mathrm{O}_{2}{ }^{-}$and $\mathrm{H}_{2} \mathrm{O}_{2}$. Decreased cardiac cell viability
\end{abstract}

Zhaohui Pei, Rongsen Meng, and Zhiqiang Zhuang contributed equally to this work.

\section{Z. Pei ( $₫)$}

Department of Cardiology, The Third Hospital of Nanchang,

Nanchang 330009, Jiangxi, China

e-mail: leak123@126.com

Z. Pei $\cdot$ Z. Zhuang

Department of Rehabilitation Medicine, The Second Affiliated

Hospital of Sun Yat-Sen University, Guangzhou, Guangdong

Province, China

R. Meng $\cdot$ Y. Zhao

Department of Cardiology, The Second People's Hospital

of Guangdong Province, Guangzhou, China

F. Liu

Department of Cardiology, The Third Affiliated Hospital of Nanchang University, Nanchang, Jiangxi Province, China

M.-Z. Zhu

Department of Physiology, The Fourth Military Medical

University, Xi'an, China

R. Li ( ()

Department of Gynecology and Obstetrics, The First Affiliated

Hospital of Jinan University, Guangzhou, China

e-mail: leak123@sina.com.cn was not observed in various time controls. A significant reduction in cardiac cell viability was observed in the infrasound group compared to the control, while significantly increased cardiac cell viability was observed in the infrasound exposure and rosiglitazone pretreatment group. Compared to the control, rosiglitazone significantly upregulated CAT, GPx, SOD1, and SOD2 expression and their activities in rat cardiomyocytes exposed to infrasound, while the levels of $\mathrm{O}_{2}{ }^{-}$or $\mathrm{H}_{2} \mathrm{O}_{2}$ were significantly decreased. A potential link between a significant downregulation of PPAR- $\gamma$ expression in rat cardiomyocytes in the infrasound group was compared to the control and infrasound-induced oxidative stress. These findings indicate that infrasound can induce oxidative damage in rat cardiomyocytes by inactivating PPAR- $\gamma$.

Keywords Infrasound exposure - Cardiomyocyte · Oxidative damage $\cdot$ PPAR $-\gamma \cdot$ Cytotoxicity

\section{Introduction}

Recently, interest in the potential adverse health effects of infrasound (generally inaudible sound with a frequency of $<20 \mathrm{~Hz}$ ) has increased [1]. Infrasound exposure is ubiquitous in modern life, generated by natural and industrial sources. Occupational Safety and Health Administration guidelines for occupational noise exposure are concerned with sound pressure levels limits $(90-115 \mathrm{~dB}$ for $0.25-8 \mathrm{~h}$ ), not frequencies [2]. The majority of infrasound effects on humans appear to be annoyance [3-5]. To achieve a given level of annoyance, low frequencies were found to require greater sound pressure. In addition, small changes in sound pressure can cause significantly large changes in annoyance in the infrasonic region [5]. 
Infrasound exposure may also cause fatigue, headache, impaired concentration, sleep disturbance, and physiological stress. Based on the known effects of infrasound, we investigated the relationship between infrasound exposure and infrasonic bioeffects by animal experiments.

Recently [6], we reported that infrasound induced hemodynamic, cardiac ultrastructure damage and cardiac cell apoptosis in rats [6]. Furthermore, L-type calcium currents in rat ventricular myocytes were modified by infrasound exposure [7]. These experimental findings suggest that there may be important regulatory roles for infrasound on the cardiovascular system.

Due to the known effects of oxidative stress on the cardiovascular system, we speculated that infrasound exposure may induce oxidative stress in cardiac cells. PPAR- $\gamma$ protects cardiomyocytes from oxidative stress in rat cardiac tissues, potentially through increased catalase expression or decreased intracellular $\mathrm{H}_{2} \mathrm{O}_{2}[8,9]$. The lack of PPAR- $\gamma$ was primarily responsible for the development of intrinsic cardiac dysfunction associated with mechanical impairment of myosin [10].

Therefore, in the present study, we tested whether infrasound induced oxidative damage and whether PPAR- $\gamma$ was involved in the regulation of infrasonic oxidative stress.

\section{Materials and Methods}

Experimental Animals and Exposure Procedures

Fifty-six neonatal male Sprague-Dawley (SD) rats (1- to 3-day-old, $12 \pm 3 \mathrm{~g}$ ) were obtained from the Center of Experimental Animal of the Fourth Military Medical University and maintained on food and water ad libitum. The rats were housed in an air-conditioned room (12/12 h light/dark cycle at a temperature of $23 \pm 2{ }^{\circ} \mathrm{C}$ and a relative humidity of $60 \pm 5 \%$ ). All rats were randomly divided into seven groups: four different time control groups and three experimental groups, with 24,48 , and $72 \mathrm{~h}$ infrasound exposure ( $n=8$ rats per group). All animal procedures were performed in accordance with institutional ethical guidelines that were approved by the animal care and use committee of the Fourth Military Medical University (Xi'an, China).

Neonatal Rat Cardiomyocytes

Neonatal rat cardiomyocytes were prepared from the left ventricle of 1- to 3-day-old Sprague-Dawley rats as described previously $[7,11]$. In order to remove fibroblasts, the cells were pre-plated and cultured at $37{ }^{\circ} \mathrm{C}$ for $90 \mathrm{~min}$. Unattached cardiomyocytes were collected, counted, and seeded in 6-well culture plates at a density of $3 \times 10^{5} /$ well. Bromodeoxyuridine $(0.1 \mathrm{mM})$ was added to the culture medium for the first $72 \mathrm{~h}$ to deplete fibroblasts, and culture medium was changed every $48 \mathrm{~h}$. Cardiomyocytes were randomly divided into seven groups: 0 -h control group, 24-h control group, 48-h control group, 72-h control group, 24-h infrasound exposure group, 48-h infrasound exposure group, and 72-h infrasound exposure group $(n=8$ rats per group). Cardiomyocytes were treated with infrasound at $5 \mathrm{~Hz}$ and $130 \mathrm{~dB}$ and/or rosiglitazone at various concentrations for $0,24,48$, and $72 \mathrm{~h}$. As previously reported by Samuel Bell D et al. [12], the concentrations of rosglitazone were effective in these experiments.

\section{Western Immunoblotting}

For the preparation of whole-cell lysates, cultured cells were washed with ice-cold PBS and lysed for $30 \mathrm{~min}$ on ice in RIPA buffer containing $150 \mathrm{mM} \mathrm{NaCl}$ as described [13]. Cell lysates were cleared at 20,000 g for $10 \mathrm{~min}$. Following adjustment for protein concentration (Bradford assay), the lysates were boiled in SDS sample-loading buffer for $5 \mathrm{~min}$ and then separated using SDS-polyacrylamide gel electrophoresis (PAGE, 4-15 \%, Bio-Rad). Gels were blotted on a polyvinylidene difluoride membrane (Immobilon P; Millipore, Bedford, MA, USA) and stained with the indicated first antibody purchased from Santa Cruz Biotechnology Inc. (Santa Cruz, CA) or Calbiohem (Cambridge, MA, USA). Antibody binding was detected using horseradish peroxidase-coupled secondary antibody followed by chemiluminescence detection (ECL Plus; Amersham Pharmacia, Uppsala, Sweden). The relative amounts of protein expression were calculated using the expression of rat alpha-actin (actin- $\alpha$ ) as an internal standard.

\section{RNA Extraction and Reverse Transcriptase PCR}

Total RNA was isolated using TRIzol reagent (Invitrogen). From each cardiac sample, $1 \mu \mathrm{g}$ of RNA was reverse transcribed using random primers, and AMV reverse transcriptase was performed according to the manufacturer's protocol (Promega). Polymerase chain reaction (PCR) was performed in a Mastercycler (Eppendorf, Germany) with the primers indicated in Table 1 . Conditions for PCR were $1 \times\left(94{ }^{\circ} \mathrm{C} \mathrm{C}\right.$ for $\left.4 \mathrm{~min}\right) ; 35 \times\left(94{ }^{\circ} \mathrm{C}\right.$ for $45 \mathrm{~s} ; 58{ }^{\circ} \mathrm{C}$ for $42 \mathrm{~s}$; and $72{ }^{\circ} \mathrm{C}$ for $\left.1 \mathrm{~min}\right)$; and $1 \times\left(72{ }^{\circ} \mathrm{C}\right.$ for $10 \mathrm{~min})$. Amplification products obtained by PCR were electrophoretically separated using a $1 \%$ agarose gel and visualized by ethidium bromide (EtBr) staining. The relative amounts of gene expression were calculated using the expression of actin- $\alpha$ as an internal standard. 
Table 1 Primers used in RT-PCR

\begin{tabular}{|c|c|}
\hline Target genes & Sequence of primers \\
\hline \multirow[t]{2}{*}{ CAT } & Sense $5^{\prime}$-ATGGCTTTTGACCCAAGCAA-3' \\
\hline & Antisense $5^{\prime}$-CGGCCCTGAAGCTTTTTGT-3' \\
\hline \multirow[t]{2}{*}{ GPx } & Sense $5^{\prime}$-GCGGGCCCTGGCATTG-3' \\
\hline & Antisense 5'-GGACCAGCGCCCATCTG-3' \\
\hline \multirow[t]{2}{*}{ SOD1 } & Sense 5'-CACTCTAAGAAACATGGCG-3' \\
\hline & Antisense 5'-CTGAGAGTGAGATCACACG-3' \\
\hline \multirow[t]{2}{*}{ SOD2 } & Sense $5^{\prime}$-TTCAGCCTGCACTGAAG-3' \\
\hline & Antisense $5^{\prime}$-GTCACGCTTGATAGCCTC-3' \\
\hline \multirow[t]{2}{*}{ PPAR- $\gamma$} & Sense $5^{\prime}$-ACT GCC TAT GAG CAC TTC AC- $3^{\prime}$ \\
\hline & Antisense $5^{\prime}$-CAA TCG GAT GGT TCT TCG GA- $3^{\prime}$ \\
\hline \multirow[t]{2}{*}{ Actin- $\alpha$} & Sense $5^{\prime}$-TCCCTGTACGCTTCTGGTCGTA-3' \\
\hline & Antisense 5'-TCTCAAAGTCCAAAGCCACATA-3' \\
\hline
\end{tabular}

Measurement of Catalase (CAT) Activity

As previously reported by Chan et al. [14], the activity of CAT from cultured cardiomyocytes was measured using the Amplex Red CAT Assay Kit (MolecularProbes, Eugene, OR, USA). In brief, reaction mixtures contained $50 \mu \mathrm{M}$ Amplex red reagent, $40 \mu \mathrm{M} \mathrm{H}_{2} \mathrm{O}_{2}, 0.2$ units $/ \mathrm{ml}$ horseradish peroxidase, and total protein ( $1 \mathrm{mg}$ protein $/ \mathrm{ml}$ ), and then, they were incubated at room temperature for $30 \mathrm{~min}$. CAT activity was determined by measuring the absorbance at $570 \mathrm{~nm}$ using a Bio-Radmicroplate reader. CAT activity (U) was calculated as the amount of sample required to hydrolyze $1 \mu \mathrm{mol}$ of $\mathrm{H}_{2} \mathrm{O}_{2}$ per minute, based on the molecular absorbance of $0.04 \times 10^{6}$ for $\mathrm{H}_{2} \mathrm{O}_{2}$.

\section{Measurement of Glutathione Peroxidase (GPx) Activity}

As previously reported by Chan et al. [14], the activity of GPx was measured using a GPx Cellular Activity Assay Kit (Sigma). Cultured cardiomyocytes were homogenized in $0.1 \mathrm{M}$ PBS and centrifuged at $13,000 \mathrm{~g}\left(4^{\circ} \mathrm{C}\right)$ for $15 \mathrm{~min}$. Fifty microliters of the supernatant was added to $950 \mu \mathrm{l}$ of $50 \mathrm{mM}$ Tris- $\mathrm{HCl}$ buffer containing $0.5 \mathrm{mM}$ EDTA, $5 \mathrm{mM}$ NADPH, $42 \mathrm{mM}$ reduced glutathione, and 10 units/ml glutathione reductase. The reaction was initiated by the addition of $30 \mathrm{mM}$ t-butyl hydroperoxide, and oxidation of NADPH was detected by monitoring the decrease in absorbance at $340 \mathrm{~nm}$. GPx activity is expressed as U/mg protein. One unit of GPx activity was defined as the amount of sample required to oxidize $1 \mu \mathrm{mol}$ of NADPH per minute, which was based on the molecular absorbance of $6.22 \times 10^{6}$ for NADPH.

Measurement of Superoxide Dismutase (SOD) Activity

The activity of SOD in cultured cardiomyocytes was measured using an SOD assay kit (Calbiochem, SanDiego,
CA, USA). The assay kit utilized 5, 6, 6a, 11b-tetrahydro3,9,10-trihydroxybenso fluorine as the substrate. This reagent undergoes alkaline autoxidation, which is accelerated by SOD, and yields a chromophore that absorbs maximally at $525 \mathrm{~nm}$. The respective activities of SOD1 or SOD2 in rat cultured cardiomyocytes were measured according to the manufacturer's instructions. A $50 \%$ inhibition was defined as 1 unit of SOD, and the specific activity is expressed as U/mg protein of rat cultured cardiomyocytes [15].

\section{Superoxide Anion $\left(\mathrm{O}_{2}^{-}\right)$Detection}

$\mathrm{O}_{2}^{-}$production was determined using lucigenin-enhanced chemiluminescence according to previously described and validated methods [12, 16, 17]. Briefly, cultured cardiomyocytes were homogenized in a $20 \mathrm{mM}$ sodium phosphate buffer ( $\mathrm{pH} 7.4)$, contained $0.01 \mathrm{mM}$ EDTA, by a glass-to-glass homogenizer. The homogenate was subjected to low-speed centrifugation at $1,000 \mathrm{~g}$ for $10 \mathrm{~min}$ at $4{ }^{\circ} \mathrm{C}$ to remove nuclei and unbroken cellular debris. The pellet was discarded and the supernatant was obtained immediately for $\mathrm{O}_{2}{ }^{-}$measurement. Background chemiluminescence in a buffer $(2 \mathrm{ml})$ that contained lucigenin $(5 \mu \mathrm{M})$ was measured for $5 \mathrm{~min}$. An aliquot of $100 \mu \mathrm{l}$ of the supernatant was then added, and chemiluminescence was measured for $10 \mathrm{~min}$ at room temperature (Sirius Luminometer, Berthold, Germany). $\mathrm{O}_{2}{ }^{-}$production was calculated and expressed as $\mu \mathrm{mol} / \mathrm{min} / \mathrm{mg}$ protein. Specificity for $\mathrm{O}_{2}{ }^{-}$was determined by the addition of SOD (350 $\mathrm{U} / \mathrm{ml}$ ) into the incubation medium.

\section{Hydrogen Peroxide $\left(\mathrm{H}_{2} \mathrm{O}_{2}\right)$ Detection}

$\mathrm{H}_{2} \mathrm{O}_{2}$ production in cultured cardiomyocytes was assessed using the Amplex Red Hydrogen Peroxide/Peroxidase Assay Kit (Molecular Probes) [18, 19]. Reaction mixtures contained $50 \mu \mathrm{M}$ Amplex red reagent, 0.1 units/ml peroxidase, and cultured cardiomyocytes ( $1 \mathrm{mg}$ protein $/ \mathrm{ml}$ ) that were then incubated at room temperature for $30 \mathrm{~min}$ [18]. $\mathrm{H}_{2} \mathrm{O}_{2}$ levels were determined by measuring the absorbance at $570 \mathrm{~nm}$ and expressed as $\mathrm{pmol} / \mathrm{min} / \mathrm{mg}$ protein using a standard curve.

\section{Cell Viability Assay}

Cardiac cells were seeded in 24-well plates and cultured as mentioned above. 3,4,5-Dimethylthiazol-2-yl-2,5-diphenyltetrazolium (MTT) (Sigma) was dissolved in PBS containing $0.5 \mathrm{~g} / \mathrm{l}$ glucose and $10 \mathrm{mg} / 1 \mathrm{CaCl}_{2}$ at a concentration of $1 \mathrm{mg} / \mathrm{ml}$. Cells were washed twice with PBS and then incubated with the MTT solution for $1.5 \mathrm{~h}$ at $37{ }^{\circ} \mathrm{C}$. Cells were then lysed with propan-2-ol and $\mathrm{HCl}$ 
$(0.1 \mathrm{~N})$, and then, the medium was transferred into 96-well plates. Absorbance of the reaction solution at $620 \mathrm{~nm}$ was measured using an ELISA plate reader (Titertek Multiskan $\mathrm{MCC} / 340)$.

\section{Statistical Analyses}

Data are expressed as mean \pm SEM. Statistical analyses were performed using SPSS, version 13.0 (SPSS Science, Chicago, IL, USA). $P<0.05$ was considered significant. The differences between the means were determined using one-way analysis of variance (ANOVA). If significant, group means were compared using least significant difference methods for multiple comparisons of means.

\section{Results}

Infrasound Exposure Induced Oxidative Stress in Rat Cardiomyocytes.

In order to determine whether infrasound was associated with cardiac oxidative damage, rats were exposed to infrasound at $5 \mathrm{~Hz}$ and $130 \mathrm{~dB}$ for $0,24,48$, and $72 \mathrm{~h}$, respectively. Untreated rats served as time controls. As shown in Fig. 1, the expression of CAT, GPx, SOD1, and

A



B



Fig. 1 The expression of CAT, GPx, SOD1, and SOD2 in cultured rat myocytes which were exposed to infrasound of $5 \mathrm{~Hz}$ at $130 \mathrm{~dB}$ for $0,24,48$, and $72 \mathrm{~h}$, respectively, with untreated myocytes as control. a Representative immunoblots. b Quantitation of CAT, GPx, SOD1, and SOD2 relative protein levels, the intensities of CAT, GPx, SOD1, and SOD2 products were normalized to those of human actin- $\alpha$
SOD2 was significantly decreased in the cardiac cells in the infrasonic exposure group in a time-dependent manner. As shown in Fig. 2, the enzyme activities of CAT, GPx, SOD1, and SOD2 were significantly decreased in the cardiomyocytes from the infrasonic exposure group in a time-dependent manner. Compared with time controls, the

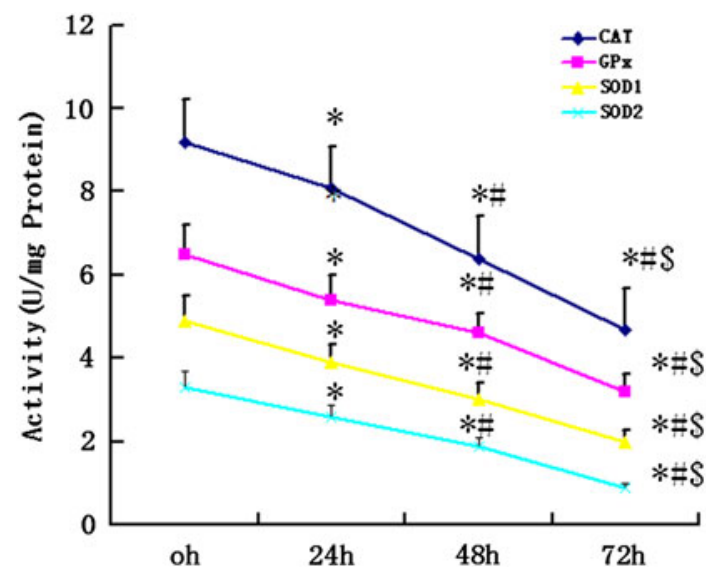

Fig. 2 Measurement of enzyme activities of CAT, GPx, SOD1, and SOD2 in the myocytes which were exposed to infrasound of $5 \mathrm{~Hz}$ at $130 \mathrm{~dB}$ for $0 \mathrm{~h}, 24 \mathrm{~h}, 48 \mathrm{~h}$, and $72 \mathrm{~h}$, respectively, with untreated myocytes as control. The statistical significance: $* p<0.01$ versus control $(0 \mathrm{~h}) ;{ }^{\#} p<0.01$ versus $24 \mathrm{~h}$ group; ${ }^{\$} p<0.01$ versus $48 \mathrm{~h}$ group. Mean $\pm \operatorname{SE}(n=8)$

C

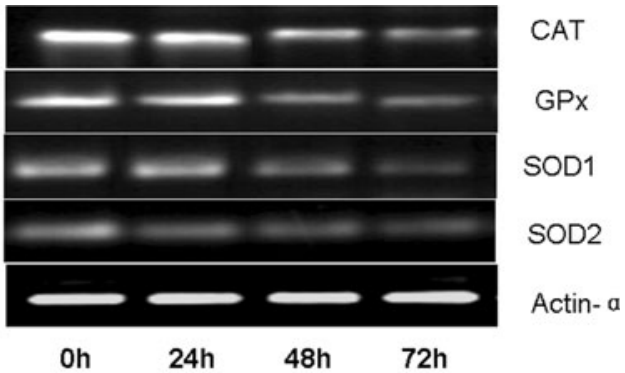

D

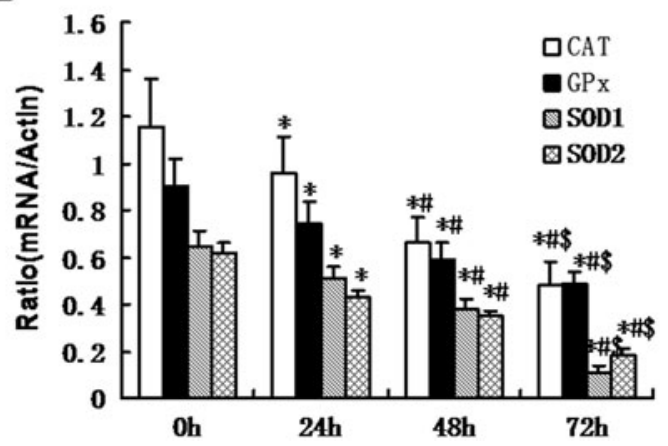

products as ratios to produce arbitrary units. c RT-PCR results of CAT, GPx, SOD1, and SOD2 mRNA. d Relative expression of CAT, GPx, SOD1, and SOD2 mRNA normalized with the internal marker human actin- $\alpha$. The statistical significance: $* p<0.01$ versus control $(0 \mathrm{~h}) ;{ }^{\#} p<0.01$ versus $24 \mathrm{~h}$ group; ${ }^{\$} p<0.01$ versus $48 \mathrm{~h}$ group. Mean $\pm \operatorname{SE}(n=8)$ 


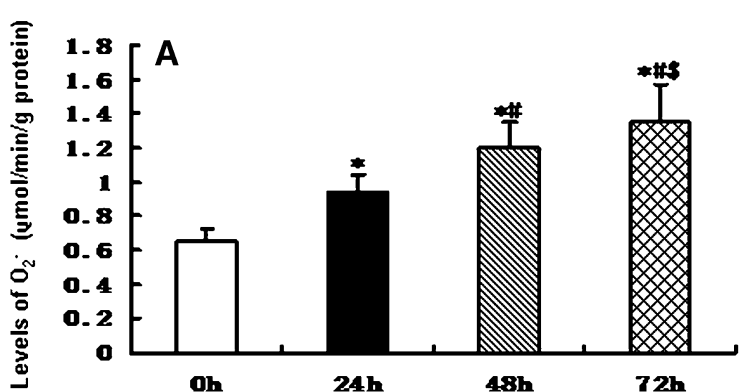

Fig. 3 Levels of $\mathrm{O}_{2}{ }^{-}$and $\mathrm{H}_{2} \mathrm{O}_{2}$ detected in rat myocytes which were exposed to infrasound of $5 \mathrm{~Hz}$ at $130 \mathrm{~dB}$ for $0,24,48$, and $72 \mathrm{~h}$, respectively, with untreated myocytes as control. a The effect of infrasound on the levels of $\mathrm{O}_{2}{ }^{-}$in cultured rat myocytes. $\mathbf{b}$ The effect

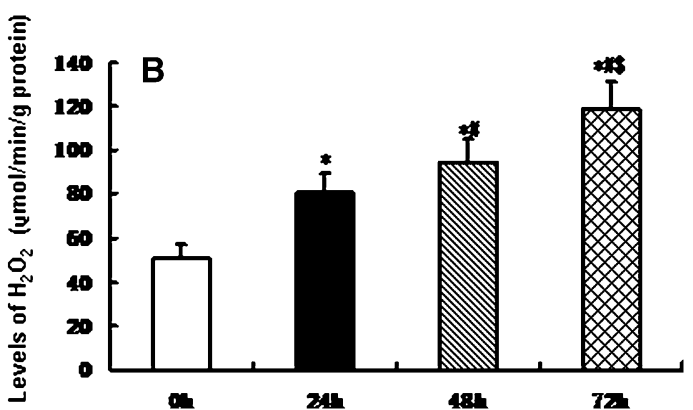

of infrasound on the levels of $\mathrm{H}_{2} \mathrm{O}_{2}$ in cultured rat myocytes. The statistical significance: ${ }^{*} p<0.01$ versus control $(0 \mathrm{~h}) ;{ }^{\#} p<0.01$ versus 24 h group; ${ }^{\$} p<0.01$ versus 48 h group. Mean $\pm \operatorname{SE}(n=8)$
A
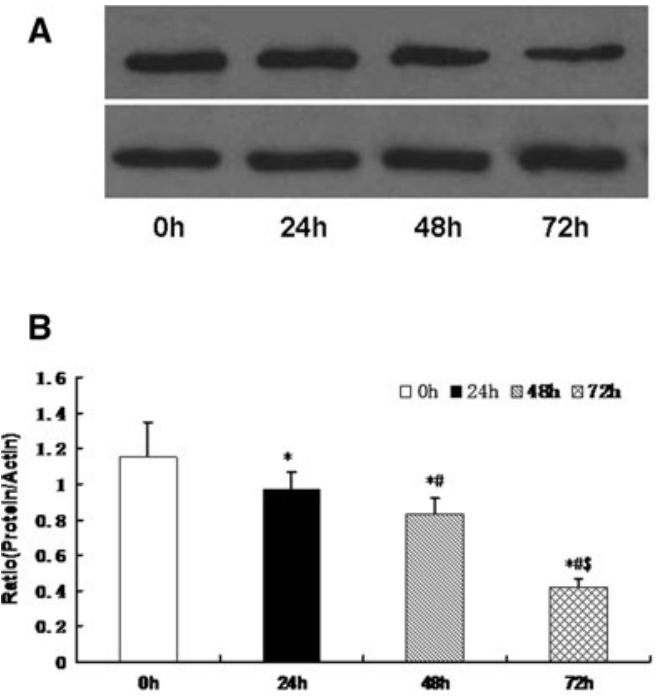

Fig. 4 The expression of PPRA- $\gamma$ in cultured rat myocytes was exposed to infrasound of $5 \mathrm{~Hz}$ at $130 \mathrm{~dB}$ for 24,48 , and $72 \mathrm{~h}$, respectively, with untreated myocytes as control. a Representative immunoblots of PPRA- $\gamma$ in cultured cardiac cells. b Quantitation of PPRA- $\gamma$ relative protein levels in cultured cardiac cells, the intensities of PPRA- $\gamma$ products were normalized to those of human actin- $\alpha$

levels of $\mathrm{O}_{2}{ }^{-}$or $\mathrm{H}_{2} \mathrm{O}_{2}$ were significantly higher in the cardiomyocytes from the infrasonic exposure group, as compared to controls (Fig. 3).

\section{Infrasound Exposure Decreased PPAR- $\gamma$ Expression in Cultured Rat Cardiomyocytes}

It has been reported that declined expression of PPAR- $\gamma$ protein in heart cells is associated with an increase in cardiac oxidative stress [17]. We examined the involvement of PPAR- $\gamma$ in cultured cardiomyocytes exposed to infrasound. Compared with the time controls, PPAR- $\gamma$ expression was significantly decreased in the infrasoundexposed group (Fig. 4).
C

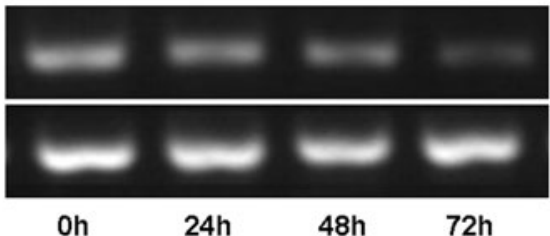

PPAR- $x$

Actin- $\alpha$

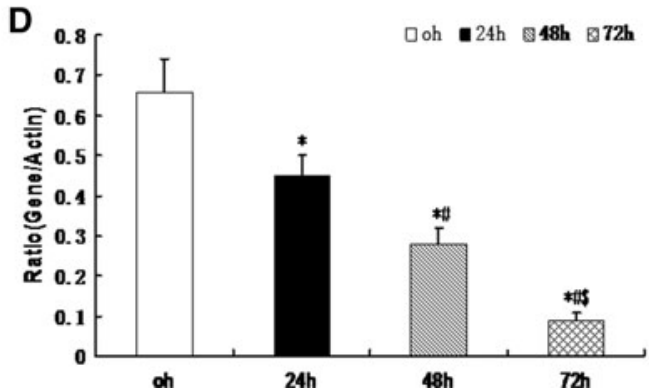

products as ratios to produce arbitrary units. (C) RT-PCR results of PPRA- $\gamma$ mRNA cultured cardiac cells. (D) Relative expression of PPRA- $\gamma$ mRNA normalized with the internal marker actin- $\alpha$. The statistical significance: ${ }^{*} p<0.01$ versus control $(0 \mathrm{~h}) ;{ }^{*} p<0.01$ versus 24 h group; ${ }^{\$} p<0.01$ versus $48 \mathrm{~h}$ group. Mean $\pm \operatorname{SE}(\mathrm{n}=8)$

The PPAR- $\gamma$ Agonist Rosiglitazone Attenuated Infrasound-Induced Cytotoxicity

Using the MTT cytotoxicity test, we examined whether the cytoprotective effects of rosiglitazone prevented infrasound-induced oxidative stress. We first pretreated the cells with concentrations of rosiglitazone ranging from 10 to $1,000 \mathrm{nM}$. Compared to the different controls, the reduction in cell viability was not observed in a concentrationdependent manner in the different concentration rosiglitazone pretreatment groups (Fig. 5a). We then determined the cytotoxicity of infrasound at $5 \mathrm{~Hz}$ and $130 \mathrm{~dB}$ from $24 \mathrm{~h}$ to $72 \mathrm{~h}$. A significant decrease in cell viability was observed $(p<0.01)$ in a time-dependent manner in the 

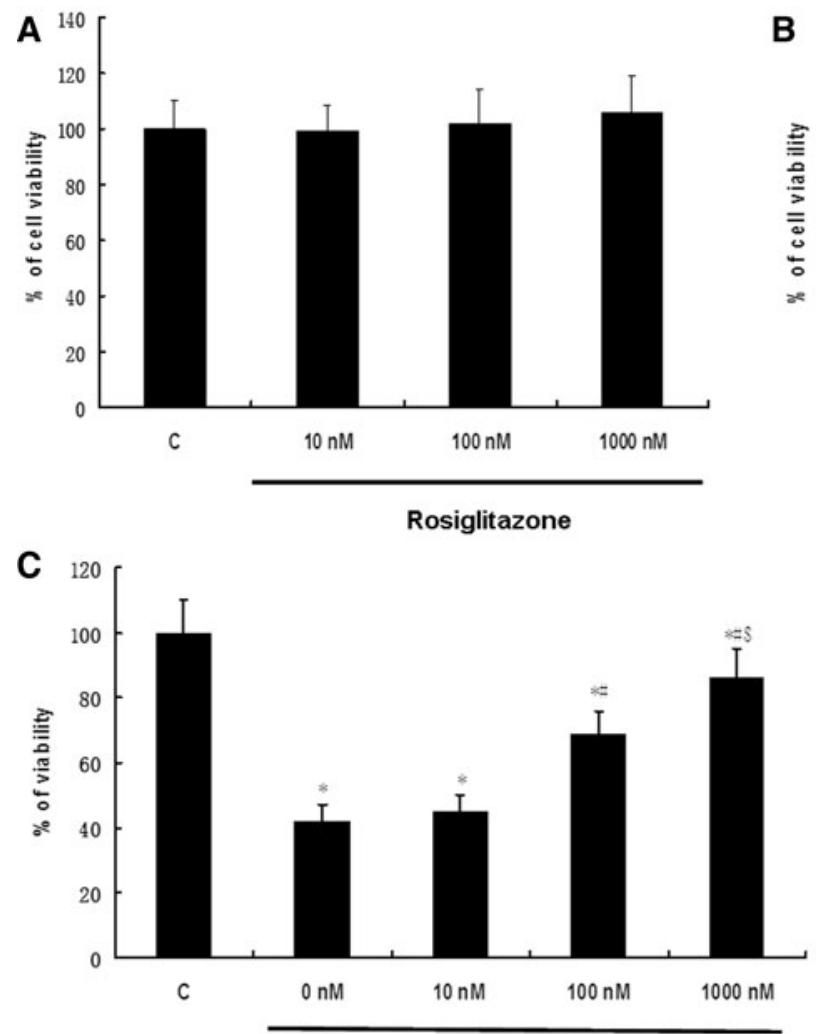

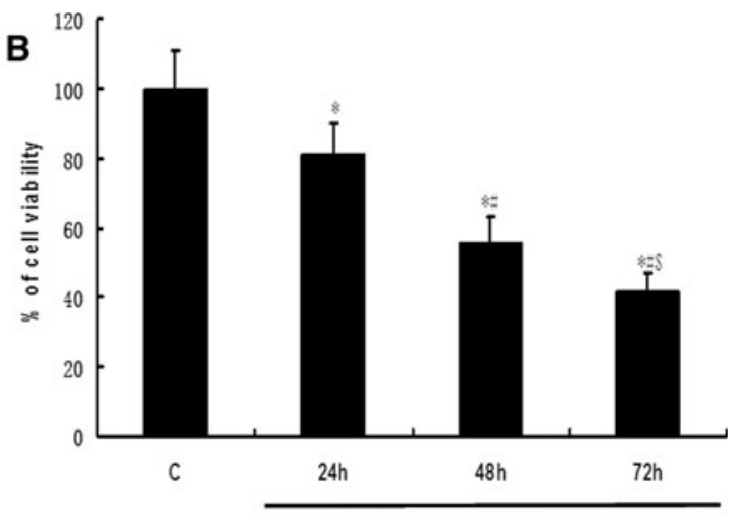

Infrasound of $130 \mathrm{~dB}$ at $5 \mathrm{~Hz}$ at different time

Rosiglitazone and infrasound of $130 \mathrm{~dB}$ at $5 \mathrm{~Hz}$ for $72 \mathrm{~h}$

Fig. 5 The changes of cell viability of cultured rat myocytes exposed to infrasound of $5 \mathrm{~Hz}$ at $130 \mathrm{~dB}$ for 24,48 , and $72 \mathrm{~h}$, respectively, with untreated myocytes as control. a The changes of cell viability of cultured rat myocytes in rosiglitazone (from 10 to $1,000 \mathrm{nM}$ ) pretreatment groups. b The changes of cell viability of cultured rat myocytes in infrasound exposure groups from 24 to $72 \mathrm{~h}$. (I). The statistical significance: $* p<0.01$ versus control $(0 \mathrm{~h}) ; \# p<0.01$

infrasound exposure group (Fig. 5b) compared to control. As shown in Fig. 5c, when the cells were pretreated with rosiglitazone (from 100 to $1,000 \mathrm{nM}$ ), prior to infrasoundinduced oxidative stress for $72 \mathrm{~h}$, there were a significant decrease in cell viability $(p<0.01)$ in cardiac cells pretreated with rosiglitazone $(0 \mathrm{nM})$ in the infrasound group compared to control, no change in cell viability in cardiac cells pretreated with rosiglitazone $(10 \mathrm{nM})$ and a significant increase in cell viability $(p<0.01)$ in cardiac cells pretreated with rosiglitazone (from 100 to $1,000 \mathrm{nM}$ ) in a concentration-dependent manner in the infrasound and rosiglitazone pretreatment groups compared to the infrasound exposure group.

\section{Rosiglitazone Inhibited Infrasound-Induced Oxidative Stress}

Cultured rat cardiomyocytes were randomized into a control group with untreated cells $(\mathrm{C})$, an infrasound exposure versus $24 \mathrm{~h}$ group; $\$ p<0.01$ versus $48 \mathrm{~h}$ group. c The changes of cell viability of cultured rat myocytes in infrasound exposure (for $72 \mathrm{~h}$ ) and rosiglitazone pretreatment (from 10 to $1,000 \mathrm{nM}$ ) group $(\mathrm{I}+\mathrm{R})$. The statistical significance: $* p<0.01$ versus control; $\# p<0.01$ versus rosiglitazone of $10 \mathrm{Mn}$ group; $\$ P<0.01$ versus rosiglitazone of $100 \mathrm{Mn}$ group. Mean $\pm \mathrm{SE}(n=8)$

group (I), and an infrasound exposure and rosiglitazone $(1,000 \mathrm{nM})$ pretreatment group $(\mathrm{I}+\mathrm{R})$, respectively. Cardiomyocytes were exposed to infrasound at $130 \mathrm{~dB}$ and $5 \mathrm{~Hz}$ for $72 \mathrm{~h}$ in the infrasound exposure group. As shown in Fig. 6, the expression of CAT, GPx, SOD1, and SOD2 was significantly decreased in the infrasound exposure group and in the infrasound exposure and rosiglitazone pretreatment group compared to control $(p<0.01)$ and significantly increased $(p<0.01)$ in the infrasound exposure and rosiglitazone pretreatment group compared to the infrasound exposure group. As shown in Fig. 7, the enzyme activity of CAT, GPx, SOD1, and SOD2 was significantly decreased $(p<0.01)$ in the infrasound exposure group and in the infrasound exposure and rosiglitazone pretreatment group compared to control and significantly increased $(p<0.01)$ in the infrasound exposure and rosiglitazone treatment group compared to the infrasound exposure group. In addition, as shown in Fig. 8, the levels of $\mathrm{O}_{2}{ }^{-}$or $\mathrm{H}_{2} \mathrm{O}_{2}$ were significantly increased $(p<0.01)$ in the 
A

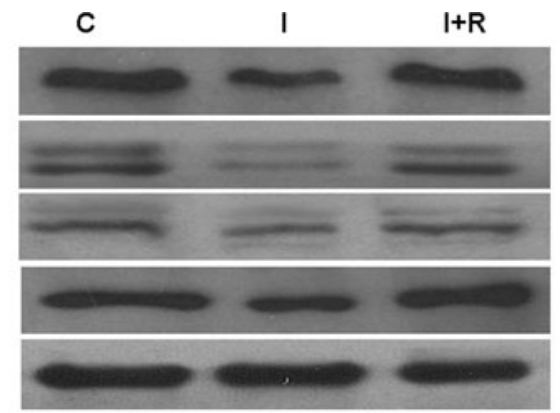

B

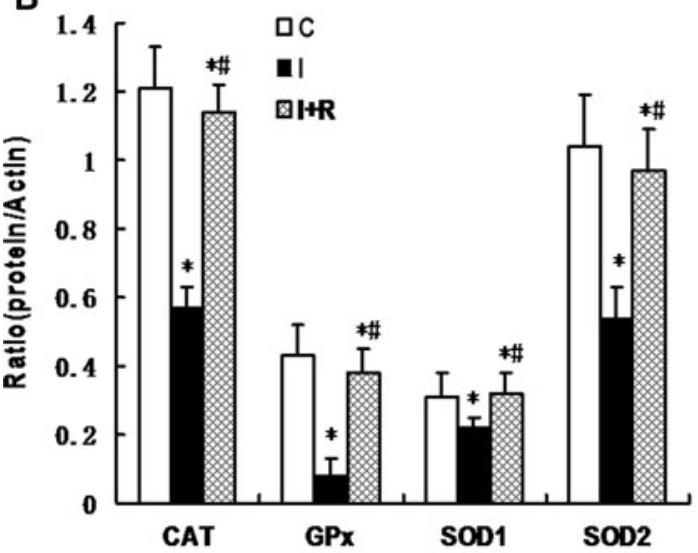

Fig. 6 The effect of rosiglitazone on the expression of CAT, GPx, SOD1, and SOD2 in cultured rat myocytes exposed to infrasound of $5 \mathrm{~Hz}$ at $130 \mathrm{~dB}$ for $72 \mathrm{~h}$. Cultured rat myocytes were randomized into control group with untreated cells $(\mathrm{C})$, infrasound exposure group (I) and infrasound exposure and rosiglitazone $(1,000 \mathrm{nM})$ pretreatment group $(I+R)$, respectively. a Representative immunoblots. b Quantitation of CAT, GPx, SOD1, and SOD2 relative protein

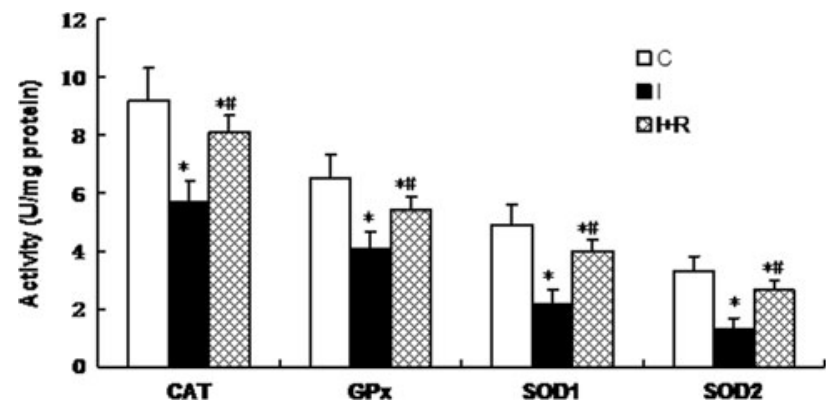

Fig. 7 The effect of rosiglitazone on the activities of CAT, GPx, SOD1, and SOD2 in cultured rat myocytes exposed to infrasound of $5 \mathrm{~Hz}$ at $130 \mathrm{~dB}$ for $72 \mathrm{~h}$. Cultured rat myocytes were randomized into control group with untreated cells $(\mathrm{C})$, infrasound exposure group (I) and infrasound exposure and rosiglitazone $(1,000 \mathrm{nM})$ pretreatment group $(I+R)$, respectively. The statistical significance: ${ }^{*} p<0.01$ versus control; ${ }^{\#} p<0.01$ versus infrasound exposure group. Mean $\pm \mathrm{SE}(n=8)$

infrasound exposure group compared to the control and significantly decreased $(p<0.01)$ in the infrasound exposure and rosiglitazone pretreatment group compared to the control and the infrasound exposure group.
C

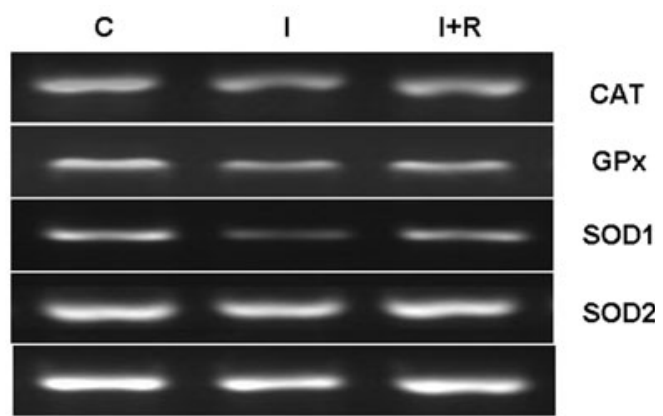

D

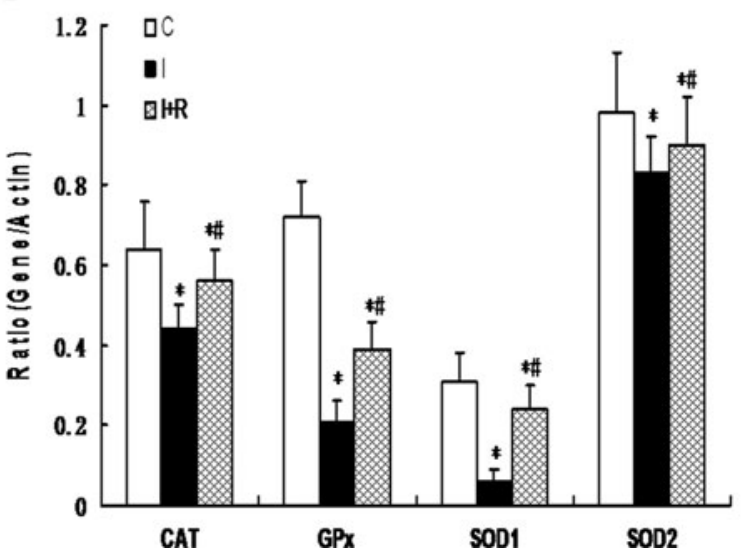

levels, the intensities of CAT, GPx, SOD1, and SOD2 products were normalized to those of human actin- $\alpha$ products as ratios to produce arbitrary units. (C) RT-PCR results of CAT, GPx, SOD1, and SOD2 mRNA. (D) Relative expression of CAT, GPx, SOD1, and SOD2 mRNA normalized with the internal marker human actin- $\alpha$. The statistical significance: ${ }^{*} p<0.01$ versus control; ${ }^{\#} p<0.01$ versus infrasound exposure group. Mean $\pm \mathrm{SE}(n=8)$

\section{Discussion}

High pressure levels of infrasound may induce resonance responses in body cavities [1, 20]. Man-made infrasonic sources and the potential harm of infrasound are increasing. Infrasound causes biological resonance, which can directly and indirectly induce a series of bioeffects. Some infrasound exposures result in death of the whole organism, organs, tissues, and cells [20]. In this study, we investigated the action of infrasound and analyzed its underlying mechanisms during the course of oxidative damage.

The present study provides novel evidence to suggest that a reduction in gene expression, protein expression, and antioxidant enzyme activities of CAT, GPx, SOD1, and SOD2 is associated with an increase in $\mathrm{O}_{2}{ }^{-}$or $\mathrm{H}_{2} \mathrm{O}_{2}$ levels in cultured rat cardiomyocytes [21-23]. We also demonstrated that these biochemical correlates of oxidative stress are related to oxidative damage by reduced expression or decreased activities of antioxidant enzymes and augmented oxidant $\mathrm{O}_{2}{ }^{-}$or $\mathrm{H}_{2} \mathrm{O}_{2}$ levels in cultured cardiomyocytes. 


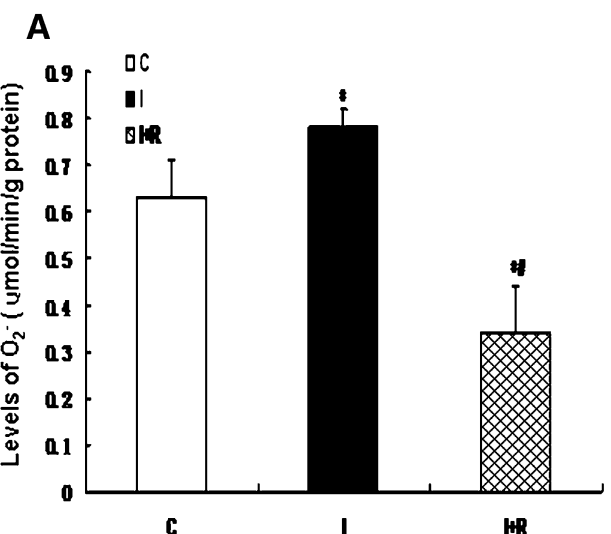

Fig. 8 The effect of rosiglitazone on the levels of $\mathrm{O}_{2}{ }^{-}$and $\mathrm{H}_{2} \mathrm{O}_{2}$ in cultured rat myocytes exposed to infrasound of $5 \mathrm{~Hz}$ at $130 \mathrm{~dB}$ for $72 \mathrm{~h}$. Cultured rat myocytes were randomized into control group with untreated cells (C), infrasound exposure group (I), and infrasound exposure and rosiglitazone $(1,000 \mathrm{nM})$ pretreatment group $(I+R)$,

Our experimental findings revealed that gene expression, protein expression, and antioxidant enzyme activities of SOD1, SOD2, CAT, and GPx were significantly reduced in cultured cardiomyocytes exposed to infrasound (Figs. 1 and 2). This decrease in gene expression, protein expression, and antioxidant enzyme activities of SOD1, SOD2, CAT, and GPx was accompanied by a significantly augmented oxidative stress, as exemplified by an increased level of $\mathrm{O}_{2}{ }^{-}$or $\mathrm{H}_{2} \mathrm{O}_{2}$ in cultured rat cardiomyocytes from exposed animals (Fig. 3). In fact, it has been reported that $\mathrm{GP}_{\mathrm{X}}$ mRNA levels are increased in skeletal muscle cells treated with $\mathrm{H}_{2} \mathrm{O}_{2}$ [19]. Elimination of $\mathrm{H}_{2} \mathrm{O}_{2}$ is critical to protect heart tissue from oxidative stress. Superoxide is converted to $\mathrm{H}_{2} \mathrm{O}_{2}$ by SOD in the presence of myocytes, while $\mathrm{H}_{2} \mathrm{O}_{2}$ forms one of the most toxic oxygen free radicals. In the myocardium, GPx plays an important role in the scavenging of $\mathrm{H}_{2} \mathrm{O}_{2}$, while CAT, the other major $\mathrm{H}_{2} \mathrm{O}_{2}$ scavenging enzyme, has very low activity [21]. The actions of SOD1, SOD2, and CAT are similar to those of GPx in the course of infrasonic oxidative damage.

PPARs are members of the nuclear receptor superfamily. Cardiomyocytes express all three PPAR subtypes $(\alpha, \beta / \delta$, and $\gamma$ ). It is now clear that PPAR- $\gamma$ plays a critical role in myocardial fatty acid oxidation [24]. In this study, oxidative stress appeared to be linked to profound alterations in SOD expression and activity. As a potential link between the downregulation of the PPAR- $\gamma$ pathway and the progression of cardiac dysfunction, functional PPAR- $\gamma$ is required to regulate cellular oxidant-antioxidant balance, prevent oxidative damage, and preserve contractile function in cardiac muscle [21-23]. In our study, the expression levels of PPAR- $\gamma$ were all significantly decreased in myocytes from infrasound-exposed animals in a timedependent manner (Fig. 4), which may be responsible for infrasonic oxidative damage.
B

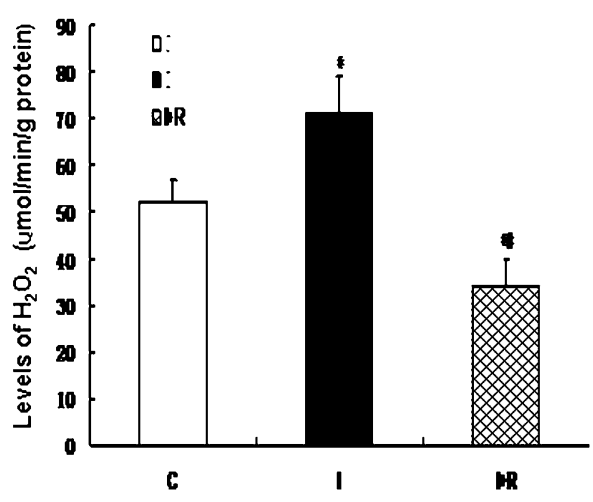

respectively. a The effect of rosiglitazone on the levels of $\mathrm{O}_{2}{ }^{-}$in cultured rat myocytes. $\mathbf{b}$ The effect of rosiglitazone on the levels of $\mathrm{H}_{2} \mathrm{O}_{2}$ in cultured rat myocytes. The statistical significance: ${ }^{*} p<0.01$ versus control; ${ }^{\#} p<0.01$ versus infrasound exposure group. Mean $\pm \operatorname{SE}(n=8)$

Rosiglitazone is a PPAR- $\gamma$ selective agonist. In our experiment, PPAR- $\gamma$ inactivation was observed in the infrasound exposure group. Infrasound induced a significant decrease in cell viability, as measured by the MTT test, significantly higher levels of $\mathrm{O}_{2}{ }^{-}$and $\mathrm{H}_{2} \mathrm{O}_{2}$, and significantly decreased mRNA and protein expression levels of CAT, GPx, SOD1 and SOD2. Compared to the cell viability of the infrasound exposure group, cell viability was significantly increased in the infrasound and rosiglitazone pretreatment group, along with significantly decreased levels of $\mathrm{O}_{2}^{-}$and $\mathrm{H}_{2} \mathrm{O}_{2}$ and significantly increased mRNA and protein expression levels of CAT, GPx, SOD1 and SOD2. Our study demonstrates that PPAR- $\gamma$ is involved in the regulation of infrasonic oxidative stress. Cells pretreated with the PPAR- $\gamma$ selective agonist rosiglitazone inhibited infrasound-induced oxidative stress. Indeed, PPAR- $\gamma$ activation led to inhibition of $\mathrm{H}_{2} \mathrm{O}_{2}$ and $\mathrm{O}_{2}{ }^{-}$and upregulated the expression of the antioxidants CAT, GPx, SOD1, and SOD2. Therefore, rosiglitazone may protect from infrasound-induced oxidative stress.

Previously, Zhaohui Pei et al. [1, 20] reported that infrasound affected the apoptotic rates of rat cardiomyocytes. This suggests that the apoptotic-inducing effects of infrasound may be cell-specific, and cardiomyocytes might be more sensitive to infrasound than other types of cells [1]. Rats exposed to 8 or $16 \mathrm{~Hz}$ at $120-140 \mathrm{~dB}$ for up to 40 days showed reduced oxidation-reduction (redox) enzymes in the myocardium, disturbed blood flow, myofibrillar fragmentation, and RNA and DNA alterations $[14,25]$. Thus, it is important to protect the heart from infrasound damage. In addition, rats acutely exposed to infrasonic oscillations for 15, 30, and $60 \mathrm{~min}$ showed frequency-dependent phasic changes in cholinergic activity, as determined by measurements of acetylcholine and acetylcholinesterase [26]. 
In summary, acute infrasound exposure induces oxidative damage of cardiomyocytes that affects a series of oxidative damage-related proteins and genes, suggesting a complex signaling network that is evoked by infrasound. PPAR $-\gamma$ is also involved in infrasonic cardiac oxidantantioxidant balance.

Acknowledgments This work was supported by the National Natural Science Foundation of China (No. 200025370).

Open Access This article is distributed under the terms of the Creative Commons Attribution License which permits any use, distribution, and reproduction in any medium, provided the original author(s) and the source are credited.

\section{References}

1. Pei, Z. H., Chen, B. Y., Tie, R., Zhang, H. F., Zhao, G., Qu, P., et al. (2011). Infrasound exposure induces apoptosis of rat cardiac myocytes by regulating the expression of apoptosis-related proteins. Cardiovascular Toxicology, 11, 341-346.

2. Gates, D. G. G., Kowalenko, T., Succop, P., Sanker, M., \& Farra, S. (2011). Occupational and demographic factors associated with violence in the emergency department. Advanced emergency nursing journal, 33, 303-313.

3. Harris, C. S., Sommer, H. C., \& Johnson, D. L. (1976). Review of the effects of infrasound on man. Aviation, Space and Environmental Medicine, 47, 430-434.

4. Feldmann, J., \& Pitten, F. A. (2004). Effects of low frequency noise on man-a case study. Noise Health, 7, 23-28.

5. Broner, N. J. (1978). The effects of low frequency noise on people: A review. Sound Vibration, 58, 483-500.

6. Pei, Z. H., Sang, H. F., Li, R. M., Xiao, P. X., He, J. G., Zhuang, Z. Q., et al. (2007). Infrasound-induced hemodynamics, ultrastructure, and molecular changes in the rat myocardium. Environmental Toxicology, 22, 169-175.

7. Pei, Z. H., Zhuang, Z. Q., Xiao, P. X., Chen, J. Z., Sang, H. F., Ren, J., et al. (2009). Influence of infrasound exposure on the whole 1-type calcium currents in rat ventricular myocytes. Cardiovascula Toxicology, 9, 70-77.

8. Dhalla, N. S., Temsah, R. M., \& Netticadan, T. (2000). Role of oxidative stress in cardiovascular diseases. Journal of Hypertension, 18, 655-673.

9. Geoffrey, D. G., Frederick, E. D., Steven, A. M., \& Mike, E. C. R. (2002). Identification of a functional peroxisome proliferator-activated receptor response element in the rat catalase promoter. Molecular Endocrinology, 16, 2793-2801.

10. Aziz, Guellich, Thibaud, D., Yves, L., Marc, C., Victor, Claes, Samuel, J. L., et al. (2007). Role of oxidative stress in cardiac dysfunction of $\mathrm{PPAR}^{-1-}$ mice. American journal of physiology. Heart and circulatory physiology., 293, H93-H102.

11. Lu, S. Y., Zhu, M. Z., Wang, D. S., Yu, J., Guo, H. T., \& Hu, Y. Z. (2004). Down-regulation of C type natriuretic peptide receptor by nasotrin peptide in cardiac myocytes and fibroblasts. Acta Pharmacologica Sinica, 25, 424-430.

12. Bell, D., \& McDermott, B. J. (2005). Effects of rosiglitazone and interactions with growth-regulating factors in ventricular cell hypertrophy. European Journal of Pharmacology, 508, 69-76.
13. Yu, j, Etmar, B., Ping, J., Antje, H., Moying, T., Ralf, M., et al. (2010). The EPHB6 receptor tyrosine kinase is a metastasis suppressor that is frequently silenced by promoter DNA hypermethylation in non-small cell lung cancer. Clinical Cancer Research, 16, 2275-2283.

14. Chan, S. H. H., Tai, M. H., Li, C. Y., \& Chan, J. Y. H. (2006). Reduction in molecular synthesis or enzyme activity of superoxide dismutases and catalase contributes to oxidative stress and neurogenic hypertension in spontaneously hypertensive rats. Free Radical Biology and Medicine, 40, 2028-2039.

15. Wang, M. H., Wu, L. L., Chan, K. L. H., \& Liu, J. Y. H. (2005). Increased superoxid anion in rostral ventrolatreral medulla contributes to hypretension in spontaneously hypertensive rats via interactions with nitric oxide. Free radical biology and medicine, $38,450-462$.

16. Gao, L., Wang, W., Li, Y. L., Schultz, H. D., Liu, D., Cornish, K. G., et al. (2004). Superoxide mediates sympathoexcitation in heart failure: Roles of angiotensin II and $\mathrm{NAD}(\mathrm{P}) \mathrm{H}$ oxidase. Circulation Research, 95, 937-944.

17. Latini, A., Scussiato, K., Rosa, R. B., Leipnitz, G., Llesuy, S., Bello-Klein, A., et al. (2003). Induction of oxidative stress by L-2-hydroxyglutaric acid in rat brain. Journal of Neuroscience Research, 74, 103-110.

18. Makino, A., Skelton, M. M., Zou, A. P., \& Cowley, A. W. J. (2003). Increased renal medullary $\mathrm{H} 2 \mathrm{O} 2$ leads to hypertension. Hypertension, 42, 25-30.

19. Dietrich, J. B., Mangeol, A., Revel, M. O., Burgun, C., Aunis, D., \& Zwiller, J. (2005). Acute or repeated cocaine administration generates reactive oxygen species and induces antioxidant enzyme activity in dopaminergic rat brain structures. Neuropharmacology, 48, 965-974.

20. Zhuang, Z. Q., Pei, Z. H., \& Chen, J. Z. (2007). Infrasoundinduced changes on sexual behavior in male rats and some underlying mechanisms. Environmental Toxicology and Pharmacology, 23, 111-114.

21. Catani, M. V., Savini, I., Duranti, G., Caporossi, D., Ceci, R., Sabatini, S., et al. (2004). Nuclear factor kB and activating protein 1 are involved in differentiation-related resistance to oxidative stress in skeletal muscle cells. Free radical biology and medicine, 37, 1024-1036.

22. Carmelo, B., Kang, B. Y., Jeffrey, D. R., Dean, P. J., \& Michael, C. (2010). Oxidative Stress Modulates PPAR $\gamma$ in Vascular Endothelial Cells. Free radical biology and medicine, 48, $1618-1625$.

23. Yusheng, Ren, Chengbo, S., Yan, S., Hongbing, Tan, Yuechun, $\mathrm{Wu}, \mathrm{Cu}, \mathrm{B}$., et al. (2009). PPAR gamma protects cardiomyocytes against oxidative stress and apoptosis via $\mathrm{Bcl}-2$ upregulation. Vascular Pharmacology, 51, 169-174.

24. Gordeladze, A. S., Glinchikov, V. V., \& Usenko, V. R. (1986). Experimental myocardial ischemia caused by infrasound. Gigiena Truda i Professional'nye Zabolevaniya, 6, 30-33.

25. Alekseev, S. V., Glinchikov, V. V., \& Usenko, V. R. (1985). Myocardial ischemia in rats exposed to infrasound. Gigiena Truda i Professional'nye Zabolevaniya, 8, 34-38.

26. El Midaoui, A., Wu, L., Wang, R., \& de Champlain, J. (2006). Modulation of cardiac and aortic peroxisome proliferator-activated receptor-gamma expression by oxidative stress in chronically glucose-fed rats. American Journal of Hypertension, 19, 407-412. 